\title{
Association Between Early Stage-Related Factors and Mortality in Patients with Exertional Heat Stroke: A Retrospective Study of 214 Cases
}

\author{
Shuyuan Liu, 1,2,* Ling Xing, 1,3,* \\ Qian Wang, ${ }^{4}$ Tianyu Xin, ${ }^{2}$ \\ Handing Mao,' Ye Tao, ${ }^{5}$ \\ Jinbao Zhao, ${ }^{2}$ Xin Li, ${ }^{4}$ Cong Li, \\ Qinghua Li, ${ }^{6}$ Yan Dou, ${ }^{7}$ Yixin Li, ${ }^{8}$ \\ Wei Zhang, ${ }^{9}$ Bo Ning, ${ }^{10}$ Qing Song' \\ 'Medical School of Chinese PLA, Beijing, People's \\ Republic of China; ${ }^{2}$ Emergency Department, Sixth \\ Medical Center, Chinese PLA General Hospital, \\ Beijing, People's Republic of China; ${ }^{3}$ Department of \\ Emergency, Beijing Tongren Hospital, Capital \\ Medical University, Beijing, People's Republic of \\ China; ${ }^{4}$ Emergency Department, Third Medical \\ Center, Chinese PLA General Hospital, Beijing, \\ People's Republic of China; ${ }^{5}$ Health Care \\ Department, Beijing Huangsi Aesthetic Surgery \\ Hospital, Beijing, People's Republic of China; \\ ${ }^{6}$ Department of Intensive Care Unit, The 990th \\ Hospital of Chinese PLA, Zhumadian, People's \\ Republic of China; ${ }^{7}$ Department of Intensive Care \\ Unit, The 909th Hospital of Chinese PLA, \\ Zhangzhou, People's Republic of China; \\ ${ }^{8}$ Department of Intensive Care Unit, The 910th \\ Hospital of Chinese PLA, Quanzhou, People's \\ Republic of China; ${ }^{9}$ Emergency Department, The \\ 900th Hospital of Chinese PLA, Fuzhou, People's \\ Republic of China; ${ }^{10}$ Department of Intensive Care \\ Unit, Air Force Medical Center of China, Beijing, \\ People's Republic of China
}

*These authors contributed equally to this work

Correspondence: Bo Ning Department of Intensive Care Unit, Air Force Medical Center of China, Beijing, I00 I42, People's Republic of China

Tel +86 I56I I I6I I I0

Fax +861068410099

Email boningbn@I63.com

Qing Song

Medical School of Chinese PLA, Beijing, 100853, People's Republic of China

Tel +86 I39 I I 374534

Fax $+86 \quad 1068182255$

Email songqing_sq87@I63.com
Objective: The purpose of this study is to evaluate the factors involved in the early stage of exertional heat stroke (EHS) that are associated with mortality.

Methods: In this retrospective, case-control study, patients from 11 tertiary medical centers in China were enrolled from January 1, 2012, to December 31, 2019. Demographic information, underlying diseases, ambient temperature, and relative humidity, clinical manifestations, initial body temperature, time from onset to diagnosis of EHS (including suspected), and the duration of body temperature $>38^{\circ} \mathrm{C}$ of all enrolled patients were recorded. The occurrence of organ dysfunction within $72 \mathrm{~h}$ was evaluated, and in-hospital deaths were recorded. The patients were subsequently divided into a survival group and a non-survival group. The "case" refers to patients in the non-survival group, while the "control" refers to patients without death.

Results: Of the 214 hospitalized patients with EHS, 183 survived and 31 died, and the overall mortality was $14.49 \%$ (31/214). A binary logistic regression showed that only the duration of body temperature $>38^{\circ} \mathrm{C}$ (OR $1.80,95 \%$ CI 1.34-2.42) and the number of organs damaged within $72 \mathrm{~h}$ of onset (OR 6.54, 95\% CI 2.31-18.56) were statistically significant in terms of risk of death in hospital $(\mathrm{p}<0.05)$. A goodness of fit test produced a $\mathrm{p}$-value of 0.76 . According to receiver operating characteristic curve (ROC) analysis, the areas under the curve (AUC) were 0.989 (95\% CI 0.978-1.000; $\mathrm{p}<0.05$ ) and 0.936 (95\% CI 0.896-0.976; $\mathrm{p}<0.05$ ).

Conclusion: Of the various factors involved in the early stage of the disease, the duration of high body temperature and the number of organs damaged within $72 \mathrm{~h}$ of onset were independent risk factors and predictors associated with death.

Keywords: heat stroke, exertional, cooling, mortality

\section{Introduction}

Heat stroke is the most severe type of heat-related illness and can be life-threatening. It is characterized by an increased core temperature of $>40^{\circ} \mathrm{C}$ and central nervous system abnormalities (eg, altered mental state, convulsions or coma) and is accompanied by severe multi-organ dysfunction, with high mortality. ${ }^{1,2}$ Heat stroke is divided into classic heat stroke (CHS) and exertional heat stroke (EHS) according to the pathogenesis of the condition and the population susceptible. ${ }^{3}$ CHS tends to occur in individuals with inadequate thermoregulation (eg, the elderly and infirm), in specific environments, specific types of clothing, and often in those without a history of strenuous exercise. In healthy young people, EHS mainly occurs in those who exercise vigorously during heat waves or in hot environments, such as soldiers, athletes, and heavy manual workers. EHS 
often occurs suddenly during exercise and deteriorates rapidly, leading to a high rate of misdiagnosis in the early stage and difficulty in treatment in the later stages. EHS has a high mortality rate and impacts greatly on the families of victims and wider society.

Research indicates that EHS accounts for $8.6-18 \%$ of heat-related illnesses caused by strenuous exercise. The mortality rate of EHS is not entirely clear and may be lower than that of CHS. ${ }^{4-6}$ As the understanding of the disease has improved in recent decades, researchers have found that the actual incidence of EHS may be higher than that reported in the literature. Some reports among athletes have shown that EHS, rather than cardiovascular accidents, may be the primary cause of sudden disturbance of consciousness and even sudden death in long-distance runners; furthermore, such patients rarely show a prior diagnosis of EHS. ${ }^{7,8}$ In China, although numerous EHS deaths occur every year, there is a lack of large-scale population survey data. By conducting a retrospective analysis of EHS hospitalized cases in recent years in China, this study explores the incidence of EHS and deaths occurring from the disease, as well as the relationship between early stage-related factors (demographic characteristics, meteorology, clinical features, and early intervention) and risk of death, to identify better-targeted and effective early-stage measures to reduce the incidence of death.

\section{Methods}

Data were collected from 11 medical centers in China: the First Medical Center of Chinese PLA General Hospital, Urumqi General Hospital of Chinese PLA, the Western Theater General Hospital of Chinese PLA, the Northern Theater General Hospital of Chinese PLA, the Central Theater General Hospital of Chinese PLA, the 900th Hospital of Chinese PLA, the 909th Hospital of Chinese PLA, the 910th Hospital of Chinese PLA, the 990th Hospital of Chinese PLA, Guyuan People's Hospital, and Jinhua central hospital. The medical centers were located in central, eastern, southern, western, and northern China. All hospitalized patients diagnosed with "heat illness," "heatrelated illness," "heat convulsion," "heat syncope," "heat exhaustion," "heat stroke," and "hyperthermia syndromes" from January 1, 2012, to December 31, 2019, were retrieved from the management system of the medical records of these centers. In the present study, the researchers were divided into three case review teams and provided with uniform training. Medical records were reviewed one by one to screen for patients who met the criteria for EHS diagnosis. Medical records that evidenced diagnostic disagreement were turned over to three experts in heat stroke for discussion. When two experts agreed, EHS diagnosis was confirmed. The process of case inclusion and exclusion is shown in Figure 1.

Patients' personal information was kept strictly confidential throughout the study, and each researcher signed a confidentiality agreement. Unauthorized access to the database of medical records information was prohibited.

This study was approved by the Research Ethics Committee, Sixth Medical Center, Chinese PLA General Hospital (permitted number: HZKY-PJ-2020-20). This study was conducted in accordance with the declaration of Helsinki. Written informed consent was obtained from all participants.

\section{Inclusion and Exclusion Criteria}

There was a lack of unified diagnostic criteria between the medical centers, which complicated EHS diagnostic terms. For data consistency and comparability, the case review team referred to the newly recommended diagnostic (suspected) criteria in the Expert consensus on the diagnosis and treatment of heat stroke in China, in which body temperature is not necessary for the diagnosis of EHS. The following criteria were identified: (1) in the medical history, patients engaged in high-intensity exercise with or without exposure to high ambient temperature and/or high humidity; (2) in the clinical presentation, there was functional impairment of the central nervous system (eg, coma, convulsions, delirium, and abnormal behavior); a core temperature above $40^{\circ} \mathrm{C}$; functional impairment of multiple organs $(\geq 2$; eg, liver, kidney, striated muscle, and gastrointestinal tract); and severe coagulopathy or disseminated intravascular coagulation (DIC). 1 EHS was considered if the patient met the medical history information in addition to any of the clinical presentations and if the symptoms could not be explained by other reasons.

Patients that met the following criteria were excluded from the study: (1) patients with a CHS diagnosis; (2) patients with heat syncope and heat exhaustion who may also have conscious disorders, though organ dysfunction was usually transient and should not be confused with EHS; (3) patients suspected of EHS with incomplete data due to halfway transfer or other reasons if their outcomes were not clearly known; (4) patients who did not meet the inclusion criteria, even if they were diagnosed as having EHS in their medical records, such as a lack of a clear history of strenuous exercise; (5) patients without complete core temperature records before and during hospitalization; (6) patients with infectious fever or severe 


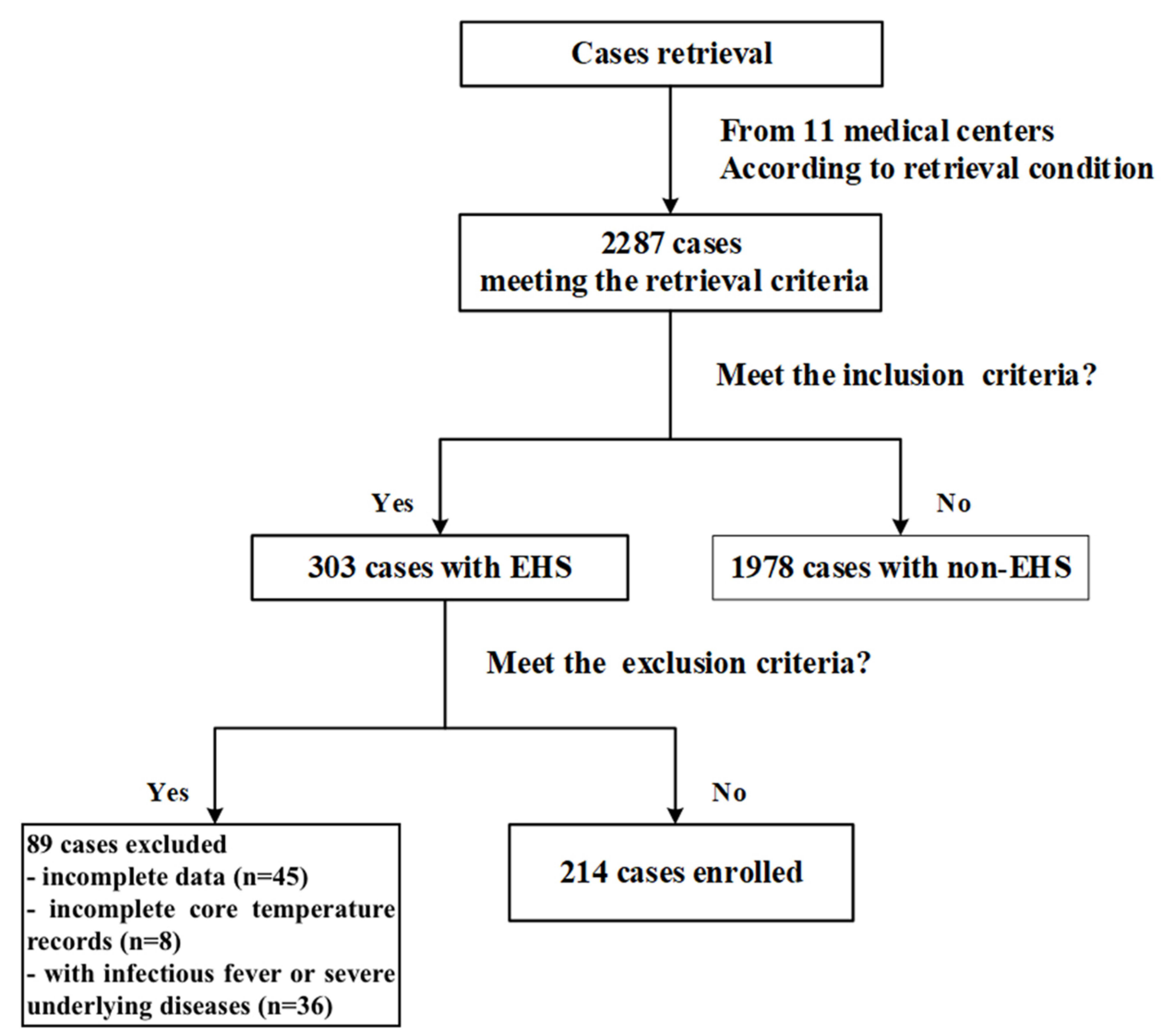

Figure I Flow chart of included and excluded cases.

underlying diseases, such as heart, liver, and kidney disease, due to possible interference with the results.

\section{Data Collection}

The following information was collected from the medical records: (1) demographic information (gender, age, height, weight, and occupation), (2) underlying diseases that may not affect body temperature and outcome measurements (eg, mild hypertension, allergic disease, diabetes without associated organ dysfunction), (3) ambient temperature and relative humidity at the time of onset, (5) the main clinical presentations (conscious status, vital signs, organ-injury-related tests, and examinations), (6) initial body temperature (the highest core body temperature measured after onset and before cooling treatment), (7) time from onset to diagnosis or suspicion of a heat-related illness. Some of the patients' medical records did not provide a specific time of diagnosis and instead referred to when cooling treatment began, such as by undoing clothing, cooling with a fan, or spraying with a water mist. It was considered that the application of such measures meant that the first responders had initially established a diagnosis or at least suspected a diagnosis of heat-related illness, and the time from onset to diagnosis was inferred from such descriptions. (8) A duration of body temperature $>38^{\circ} \mathrm{C}$ (the time from the onset to the time when the core temperature dropped below $38^{\circ} \mathrm{C}$ ) and (9) patients' outcomes during hospitalization (eg, organ dysfunction and death).

\section{Outcomes Measures}

In this retrospective, case-control study, patients were divided into a survival group and a non-survival group according to whether death occurred during hospitalization. The "case" refers to patients in the non-survival group, while the "control" refers to patients without death. Meanwhile, organ dysfunction was evaluated through clinical manifestation, tests, and by examining medical records. The number of damaged organ/systems within $72 \mathrm{~h}$ were recorded according to the following criteria.

\section{Central Nervous System}

The patient had clinical manifestations of new central nervous system damage, such as coma, general 
convulsions, delirium, and abnormal behavior, Glasgow Coma Scale (GCS) score $\leq 14$, or imaging evidence. These criteria were intended to exclude the influence of other factors, such as basic diseases or drugs. 1,9

\section{Circulatory System}

The patient satisfied either of the following: 1) hypotension: under the premise of adequate blood volume, systolic blood pressure $<90 \mathrm{mmHg}$ for $\geq 0.5 \mathrm{~h}$, or mean arterial pressure $<65 \mathrm{mmHg}$ for $\geq 0.5 \mathrm{~h}$; 2) signs of organ hypoperfusion (at least one item), mental state changes (eg, excitement or depression) excluding other causes, skin changes (eg, wet and cold or spotted), or little or no urine. $^{10}$

\section{Myocardial Injury}

Troponin I (cTnI) and creatine kinase isoenzyme (CK-Mb) were significantly increased and persisted for more than $24 \mathrm{~h} .{ }^{11}$

\section{Respiratory System}

New abnormalities in lung function testing, chest imaging, blood gas analysis, and fiberoptic bronchoscopy were used to determine impaired respiratory function. Patients with acute respiratory distress syndrome (ARDS) were also diagnosed as having impaired respiratory function. ${ }^{12}$ The above tests were performed to exclude respiratory impairment from other etiologies, such as infection.

\section{Coagulation System}

Significant bleeding (eg, skin petechiae, ecchymosis and puncture point bleeding, conjunctival bleeding, black stool, blood stool, hemoptysis, hematuria, intracranial bleeding) that could not be explained by other reasons; or diagnosis of DIC except for other reasons. The diagnostic criteria of DIC referred to the Chinese diagnostic score system. ${ }^{13}$

\section{Renal Injury}

According to the KDIGO guidelines, renal injury was diagnosed if one of the following criteria was met: blood creatinine increase $\geq 0.3 \mathrm{mg} / \mathrm{mL}(\geq 26.5 \mu \mathrm{mol} / \mathrm{L})$ within $48 \mathrm{~h}$, an increase of more than 1.5 times the upper limit in the previous seven days, or urine volume $\leq 0.5 \mathrm{~mL} /(\mathrm{kg} / \mathrm{h})$ within $6 \mathrm{~h}^{14}$

\section{Liver Injury}

Apparent jaundice (eg, sclera, skin) that could not be explained by other causes or liver function conforming to the modified Child-Pugh classification (grade B or above) were used as the basis for assessing liver function impairment. $^{15}$

\section{Rhabdomyolysis}

The diagnosis of rhabdomyolysis referred to the criteria recommended by the Chinese consensus on heat stroke in EHS patients, and applied to patients who presented with any of the following: 1) significant elevation of creatine kinase $(\mathrm{CK})$ that exceeded normal peak values by five-fold or more, or more than $1000 \mathrm{U} / \mathrm{L} ; 2$ ) significantly elevated blood and urinary myoglobin; 3) positive urine occult blood test, where no red blood cells were detected under a microscope. ${ }^{1}$

\section{Acute Gastrointestinal Injury}

The diagnosis of acute gastrointestinal injury was made based on the diagnostic criteria for acute gastrointestinal injury (AGI) recommended by the European Society of Intensive Care Medicine in 2012. ${ }^{16}$

\section{Statistical Analysis}

Data were statistically analyzed using the SPSS software package (version 26). The sample size was calculated by the SAS 9.1 Proc Power using two sample means. The Type I error probability $(\alpha)$ was 0.05 and the assurance (1- $\beta$ ) was 0.8 . The minimum sample size for the two groups were calculated to be 46 and 28, respectively. A chi-square test at a 5\% significance level was used to compare the categorical variables. If the chi-square assumptions were not satisfied, Fisher's exact tests were used. The variables were screened using the "Enter" method. The KolmogorovSmirnov tests were used for the assumptions of the normality of quantitative variables. Quantitative variables that satisfied the normal distribution were expressed as mean \pm standard deviation, and analyses of variance were used to compare the means. If the assumptions were not satisfied, the quantitative variables were expressed as median and interquartile ranges, Median (QR), and Mann-Whitney $U$-tests were used to compare the median values. A p-value $<0.05$ was considered significant.

\section{Results}

\section{General Information of Survivors and Non-Survivors}

In total, 2287 medical records were retrieved and reviewed by three medical records review teams. A total of 1466 patients were eligible for a diagnosis of 
exertional heat illness (EHI); of these patients, 303 met the EHS diagnostic criteria and were further screened. Among the hospitalized EHI patients, the total proportion of EHS was 20.67\% (303/1466). Eighty-nine patients were excluded based on the pre-established exclusion criteria. A total of 214 patients with EHS were included in the final statistical analysis, and their occupations were as military personnel, athletes, college students, and heavy manual laborers, with military personnel accounting for the majority. Of the 214 patients with EHS, 183 survived and 31 died, and the overall mortality was $14.49 \%(31 / 214)$. There was no significant difference in the baseline demographic characteristics of survivors and non-survivors $(\mathrm{P}>0.05)$. The median ambient temperature at the onset of EHS was $30.00(3.00)^{\circ} \mathrm{C}$ and 30.00 $(4.00)^{\circ} \mathrm{C}$ respectively $(\mathrm{P}>0.05)$. The median ambient relative humidity was $56.90 \quad(23.70) \%$ and 54.60 (25.00)\% respectively $(\mathrm{P}>0.05$; Table 1$)$. The missing

Table I General Information of Survivors and Non-Survivors

\begin{tabular}{|c|c|c|c|}
\hline & $\begin{array}{l}\text { Survivors } \\
(n=183)\end{array}$ & $\begin{array}{c}\text { Non-Survivors } \\
(n=31)\end{array}$ & p-value \\
\hline Age (years) & $21.00(4.00)$ & $21.00(3.00)$ & 0.722 \\
\hline \multicolumn{4}{|l|}{ Gender } \\
\hline Male & 182 & 31 & 0.680 \\
\hline Female & I & 0 & \\
\hline BMI & $22.76(2.52)$ & $23.31(3.15)$ & 0.514 \\
\hline \multicolumn{4}{|l|}{ Occupation } \\
\hline Military personnel & 163 & 25 & 0.170 \\
\hline Athletes & 7 & 4 & \\
\hline College students & 10 & 2 & \\
\hline Others* & 3 & 0 & \\
\hline \multicolumn{4}{|l|}{ Underlying diseases $\$$} \\
\hline None & 174 & 30 & 0.950 \\
\hline Hypertension & 5 & 1 & \\
\hline Diabetes & 2 & 0 & \\
\hline PSVT $^{\#}$ & 1 & 0 & \\
\hline Asthma & 1 & 0 & \\
\hline $\begin{array}{l}\text { Ambient } \\
\text { temperature }\left({ }^{\circ} \mathrm{C}\right)\end{array}$ & $30.00(3.00)$ & $30.00(4.00)$ & 0.406 \\
\hline $\begin{array}{l}\text { Ambient relative } \\
\text { humidity }(\%)\end{array}$ & $56.90(23.70)$ & $54.60(25.00)$ & 0.762 \\
\hline
\end{tabular}

Notes: BMI, body mass index, equal to weight in kilograms divided by height in meters squared. *Including 2 porters and I construction worker, none of them died. $\$$ There was no evidence of organ damage in these patients before EHS, and these underlying diseases might not affect body temperature. There were 6 patients with mild hypertension (one of them died), 2 young patients with diabetes, whose blood glucose was only mildly elevated, I patients with PSVT who did not have an attack during EHS, and I patients with history of allergic asthma who did not have an attack during EHS. ${ }^{\#}$ PSVT, paroxysmal supraventricular tachycardia. data were handled using the SPSS software and did not affect the results.

\section{Initial Body Temperature of Survivors and Non-Survivors}

The core temperature of most EHS patients before cooling treatment was between $40^{\circ} \mathrm{C}$ and $43^{\circ} \mathrm{C}$, as shown in Table 2. Five patients with EHS had an initial body temperature of $\leq 40^{\circ} \mathrm{C}$. The median initial body temperature of survivors and non-survivors was 42.00 $(1.30)^{\circ} \mathrm{C}$ and $42.00(1.60)^{\circ} \mathrm{C}$, respectively, and there was no statistical difference $(\mathrm{P}>0.05)$.

\section{The Time from Onset to Diagnosis in Survivors and Non-Survivors}

The time from onset to diagnosis of a heat-related illness (including suspected diagnosis) was calculated or inferred by the time recorded in the medical records. The length of time from onset to diagnosis was divided into nine periods: $\leq 0.5 \mathrm{~h}, 0.5-1 \mathrm{~h}$ (including), 1-2 h (including), 2-4 $\mathrm{h}$ (including), 4-8 h (including), 8-24 h (including), 24-48 $\mathrm{h}$ (including), 48-72 $\mathrm{h}$ (including), and $>72 \mathrm{~h}$. The distribution of cases in each time period is provided in Table 3. The median time from onset to diagnosis for survivors and non-survivors was $0.83(6.20) \mathrm{h}$ and 1.00 (4.59) h, respectively, and there was no statistical difference $(\mathrm{P}>0.05)$.

\section{Duration of Body Temperature $>38^{\circ} \mathrm{C}$ in Survivors and Non-Survivors}

The duration of body temperature $>38^{\circ} \mathrm{C}$ in all patients after onset was recorded, and the results are shown in Table 4. The duration of body temperature was divided into nine periods: $\leq 0.5 \mathrm{~h}, 0.5-1 \mathrm{~h}$ (including), $1-2$ $\mathrm{h}$ (including), 2-4 h (including), 4-8 h (including), 8-24 $\mathrm{h}$ (including), 24-48 h (including), 48-72 h (including), and $>72 \mathrm{~h}$. The median duration of body temperature in the survivors and non-survivors was $2.00(2.00) \mathrm{h}$ and $16.00(17.00) \mathrm{h}$, respectively, $(\mathrm{p}<0.05)$.

\section{Organ Dysfunction Within $72 \mathrm{~h}$ in Survivors and Non-Survivors}

Organ dysfunction in EHS patients within $72 \mathrm{~h}$ was evaluated, and the number of organs involved was recorded and is listed in Table 5. The median number of damaged organs in the survivors and non-survivors was 5.00 (1.00) and 8.00 (2.00), respectively, $(\mathrm{p}<0.05)$. 
Table 2 Initial Body Temperature in Survivors $(n=183)$ and Non-Survivors $(n=31)$

\begin{tabular}{|l|c|c|c|c|}
\hline Initial Body Temperature & Survivors & Non-Survivors & n (\%) & p-value \\
\hline$\leq 40^{\circ} \mathrm{C}$ & 2 & 3 & $5(2.34 \%)$ & $45(21.03 \%)$ \\
$40-41^{\circ} \mathrm{C}$ (including) & 37 & 8 & $79(36.92 \%)$ & $69(32.24 \%)$ \\
$4 I-42^{\circ} \mathrm{C}$ (including) & 72 & 7 & $16(7.48 \%)$ & \\
$42-43^{\circ} \mathrm{C}$ (including) & 58 & 11 & & 0.799 \\
$>43^{\circ} \mathrm{C}$ & 14 & 2 & & \\
\hline Median(QR) & $42.00(1.30)^{\circ} \mathrm{C}$ & $42.00(1.60)^{\circ} \mathrm{C}$ & & \\
\hline
\end{tabular}

Table 3 Time from Onset to Diagnosis in Survivors $(n=183)$ and Non-Survivors $(n=3 \mid)$

\begin{tabular}{|c|c|c|c|c|}
\hline From Onset to Diagnosis & Survivors & Non-Survivors & n (\%) & p-value \\
\hline$\leq 0.5 \mathrm{~h}$ & 75 & 20 & $95(44.39 \%)$ & \\
\hline $0.5-I h$ (including) & 13 & 3 & $16(7.48 \%)$ & \\
\hline $\mathrm{I}-2 \mathrm{~h}$ (including) & 14 & I & 15(7.01\%) & \\
\hline 2-4h (including) & 11 & I & $12(5.61 \%)$ & \\
\hline 4-8h (including) & 30 & 3 & $33(15.42 \%)$ & \\
\hline 8-24h (including) & 18 & 2 & $20(9.35 \%)$ & \\
\hline 24-48h (including) & 12 & 1 & $13(6.07 \%)$ & \\
\hline 48-72h (including) & 7 & 0 & $7(3.27 \%)$ & \\
\hline$>72 \mathrm{~h}$ & 3 & 0 & $3(1.40 \%)$ & \\
\hline Median (QR) & $0.83(6.20) h$ & $\mathrm{I} .00(4.59) \mathrm{h}$ & & 0.604 \\
\hline
\end{tabular}

Table 4 Duration of Body Temperature $>38^{\circ} \mathrm{C}$ in Survivors $(n=183)$ and Non-Survivors $(n=3 \mid)$

\begin{tabular}{|c|c|c|c|c|}
\hline Duration of High Temperature & Survivors & Non-Survivors & n (\%) & p-value \\
\hline$\leq 0.5 \mathrm{~h}$ & 5 & 0 & $5(2.34 \%)$ & \\
\hline 0.5-Ih (including) & 48 & 0 & $48(22.43 \%)$ & \\
\hline $\mathrm{I}-2 \mathrm{~h}$ (including) & 67 & 0 & $67(31.31 \%)$ & \\
\hline 2-4h (including) & 53 & 0 & $53(24.77 \%)$ & \\
\hline 4-8h (including) & 7 & 11 & $18(8.41 \%)$ & \\
\hline 8-24h (including) & 3 & 13 & $16(7.48 \%)$ & \\
\hline 24-48h (including) & 0 & 4 & $4(1.87 \%)$ & \\
\hline 48-72h (including) & 0 & 3 & $3(1.40 \%)$ & \\
\hline$>72 \mathrm{~h}$ & 0 & 0 & $0(0.00 \%)$ & \\
\hline Median (QR) & $2.00(2.00) \mathrm{h}$ & $16.00(17.00) \mathrm{h}$ & & 0.000 \\
\hline
\end{tabular}

\section{Analysis of Early Stage-Related Factors and Death Risk of EHS Patients}

To further analyze the relationship between certain early stage-related factors (eg, demographic characteristics, meteorology, clinical features, and early intervention) and death risk, a binary logistic model was established that included whether the patient died in hospital as the dependent variable, and gender, age, BMI, occupation, underlying diseases, ambient relative humidity, ambient temperature, time from onset to diagnosis, initial body temperature, duration of body temperature $>38^{\circ} \mathrm{C}$ and number of damaged organs within $72 \mathrm{~h}$ as independent variables. After the screening of the variables by using the "Enter" method, only the duration of body temperature $>$ $38^{\circ} \mathrm{C}$ (OR 1.80, 95\% CI 1.34-2.42) and the number of damaged organs within $72 \mathrm{~h}$ (OR 6.54, 95\% CI 2.3118.56) were statistically significant $(p<0.05)$. Detailed results of the logistic analysis are shown in Table 6. The results of the Hosmer and Lemeshow test yielded a chisquare of 4.93 and a p-value of 0.76 . 
Table 5 Number of Damaged Organs Within $72 h$ in Survivors $(n=183)$ and Non-Survivors $(n=31)$

\begin{tabular}{|l|c|c|c|c|}
\hline Number of Damaged Organs Within 72h & Survivors & Non-Survivors & $\mathbf{n}(\%)$ & $\mathbf{p}$-value \\
\hline 2 & 14 & 0 & $14(6.54 \%)$ \\
3 & 25 & 0 & $25(11.68 \%)$ \\
4 & 46 & 0 & $46(21.50 \%)$ \\
5 & 54 & 2 & $23(26.17 \%)$ \\
6 & 22 & 1 & $18(8.41 \%)$ \\
7 & 12 & 6 & $22(10.28 \%)$ \\
8 & 8 & 14 & $10(4.67 \%)$ \\
9 & 2 & 8 & & 0.000 \\
\hline Median(QR) & $5.00(1.00)$ & $8.00(2.00)$ & \\
\hline
\end{tabular}

Table 6 Logistic Analysis of Factors Associated with Hospital Death in Patients with EHS $(n=214)$

\begin{tabular}{|l|l|l|l|l|l|l|l|}
\hline Variable(s) & B & S.E. & Wald & p-value & \multicolumn{2}{l|}{ OR } & \multicolumn{2}{l|}{$\mathbf{9 5 \%}$ CI for OR } \\
\cline { 3 - 7 } & & & & & Lower & Upper \\
\hline Constant & & & & & & \\
Gender & 1.26 & $40,193.03$ & 0.00 & 1.00 & 3.53 & \\
Age (years) & -9.43 & $40,193.02$ & 0.00 & 1.00 & 0.00 & 0.00 & \\
BMI & -0.01 & 0.14 & 0.01 & 0.93 & 0.99 & 0.76 & 1.29 \\
Occupation & -0.23 & 0.27 & 0.74 & 0.39 & 0.80 & 0.47 & 1.34 \\
Underlying diseases & 0.47 & 0.73 & 0.42 & 0.52 & 1.60 & 0.38 & 6.70 \\
Ambient relative humidity $(\%)$ & -0.86 & 1.32 & 0.43 & 0.51 & 0.42 & 0.03 & 5.59 \\
Ambient temperature $\left({ }^{\circ} \mathrm{C}\right)$ & -0.01 & 0.04 & 0.07 & 0.79 & 0.99 & 0.92 & 1.07 \\
Time from onset to diagnosis $(\mathrm{h})$ & 0.12 & 0.11 & 1.35 & 0.24 & 1.13 & 0.92 & 1.40 \\
Initial body temperature $\left({ }^{\circ} \mathrm{C}\right)$ & -0.03 & 0.03 & 1.28 & 0.26 & 0.97 & 0.92 & 1.02 \\
Duration of body temperature $>38^{\circ} \mathrm{C}(\mathrm{h})$ & -0.17 & 0.59 & 0.09 & 0.77 & 0.84 & 0.26 & 2.69 \\
Number of damaged organs within $72 \mathrm{~h}$ & 1.88 & 0.15 & 15.16 & 0.00 & 1.80 & 1.34 & 2.42 \\
\hline
\end{tabular}

Abbreviations: B, partial regression coefficient; SE, standard error (for partial regression coefficient); OR, odds ratio; Cl, confidence interval.

\section{Predictive Value of Early Stage-Related Factors for Hospitalized Deaths}

To further analyze the prognostic value (inpatient death or not) of the duration of a body temperature $>38^{\circ} \mathrm{C}$ and the number of damaged organs within $72 \mathrm{~h}$, a receiver operating characteristic curve (ROC) was drawn with the true positive rate (sensitivity) as the ordinate and the false positive rate (1-specificity) as the abscissa (Figure 2). The areas under the curve (AUC) were 0.989 (95\% CI $0.978-1.000, \mathrm{p}<0.05)$ and 0.936 (95\% CI $0.896-0.976$, $\mathrm{p}<0.05$; Table 7). The cutoff value of the duration of body temperature $>38^{\circ} \mathrm{C}$ was $4.88 \mathrm{~h}$, the maximum Youden index was 0.962 , the sensitivity (Se) was $100 \%$, and the specificity (Sp) was $96.2 \%$. The cutoff value of the number of damaged organs within $72 \mathrm{~h}$ was 6.5 , the maximum Youden index was 0.783 , the Se was $90.3 \%$, and the Sp was $88.0 \%$.

\section{Discussion}

EHS mainly occurs in a specific population and is sporadic. Although the condition has a high mortality rate, the incidence of EHS in the human disease spectrum is relatively low. Studying large-sample cases often presents difficulties involving limitations in time, region, administration, and other factors. ${ }^{17}$ Morbidity and mortality data reported by different studies vary widely, and more detailed data have mainly been reported from the military. ${ }^{6,18}$ The present study was supported by a network of experts in heat stroke prevention and control in China, which aided the collection of medical records from various centers. All cases included in the present study were from tertiary medical centers; there were a total of 214 included cases and 31 deaths, with a total mortality of $14.49 \%$. It should be noted that this mortality likely overestimates the true numbers, as the medical 


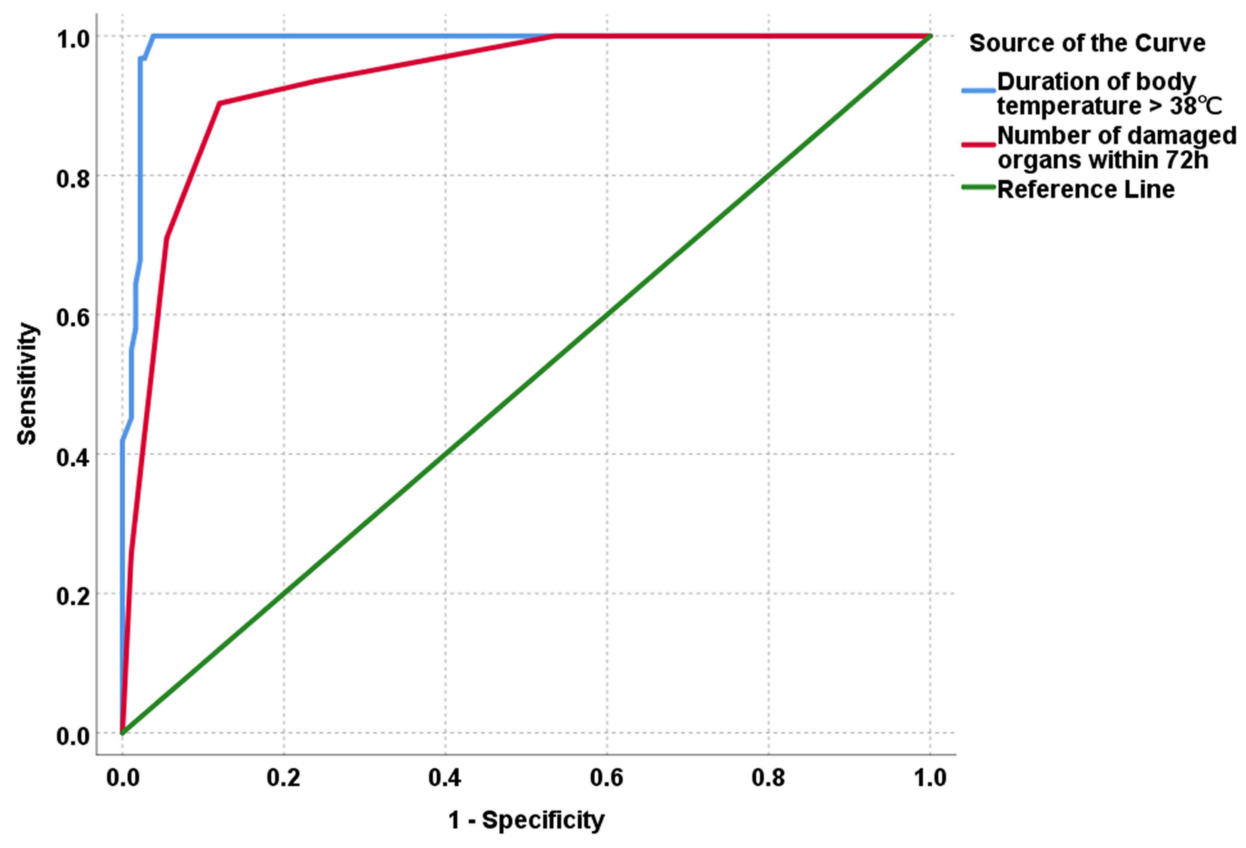

Figure 2 Receiver operating characteristic curve of early stage-related factors to predict death. The occurrence of in-hospital death is the outcome dichotomous variable, and the duration of body temperature $>38^{\circ} \mathrm{C}$ and the number of damaged organs within $72 \mathrm{~h}$ are the predictors as shown. Both showed a large area under the ROC, which was suggestive of a good ability to predict in-hospital death.

records of deaths tended to be relatively well-documented and were rarely excluded (rarely meeting exclusion criteria). In addition, EHS cases admitted to tertiary medical centers were often more serious than patients admitted to secondary hospitals, and a considerable number of severe cases were transferred from secondary hospitals to tertiary hospitals, which means that EHS patients admitted to secondary and lower hospitals may not have such high mortality.

At present, body temperature is the most direct indicator of heat stress and risk of heat injury, although it is not a perfect indicator and remains controversial. ${ }^{19}$ When studying heat stress, the core temperature should be used for the body temperature rather than the surface temperature as surface temperature measurements are susceptible to a variety of factors, and their accuracy is uncertain. In the present study, the selected patients all had relatively complete core temperature measurement records. Five patients with EHS had an initial body temperature below $40^{\circ} \mathrm{C}$. This may lead to doubts about the diagnosis as heat stroke patients are traditionally thought to have a body temperature of $>40^{\circ} \mathrm{C}^{20}$ In fact, these five patients all exhibited impairment of more than two organs with continuous progression, and two of them died. This suggests that although increased core temperature is a typical feature of EHS, it is inappropriate to list a body temperature of $>40^{\circ} \mathrm{C}$ as a necessary condition for EHS diagnosis. Furthermore, in some cases, core temperature measurements were conditioned. Concerns have been raised that placing too great an emphasis on the diagnostic necessity of the "temperature" threshold may delay the diagnosis and appropriate treatment of certain patients. In view of this, the Japanese Association for Acute Medicine (JAAM) issued new diagnostic criteria (modified JAAM criteria)

Table 7 Area Under the Receiver Operating Characteristic Curve

\begin{tabular}{|l|l|l|l|l|l|}
\hline Variable(s) & Area & SE & \multirow{2}{*}{ p-value } & \multicolumn{2}{l|}{ 95\% Cl for AUC } \\
\cline { 3 - 6 } & & & & Lower & Upper \\
\hline Duration of body temperature $>38^{\circ} \mathrm{C}$ & 0.989 & 0.006 & 0.000 & 0.978 & 1.000 \\
Number of damaged organs & 0.936 & 0.020 & 0.000 & 0.896 & 0.976 \\
\hline
\end{tabular}

Abbreviations: AUC, area under curve; SE, standard error (of $\mathrm{AUC}$ ); $\mathrm{Cl}$, confidence interval. 
for heat stroke in 2018 that excluded body temperature. Subsequently, in 2020, the Expert consensus on the diagnosis and treatment of heat stroke in China was published and did not include body temperature as a necessary factor for diagnosis. ${ }^{1,21}$

It is generally thought that delayed diagnosis is an important contributor to poor prognosis. However, in the analysis of 214 EHS cases in the present study, most patients were diagnosed or suspected in the early stages after onset, and $44.39 \%$ of diagnoses were established within 30 minutes. No significant difference was noted in the time from onset to diagnosis among survivors and nonsurvivors. A logistic analysis also showed no significant correlation between delayed diagnosis and death. A possible explanation for this is that after the onset of the disease, patients are usually prevented from engaging in physical activity, removed from the onset environment, and sent to a medical institution. These routine measures may alleviate the disease in less severe patients, regardless of whether a diagnosis is established in the first place.

Through logistic analysis, this study showed that the duration of high body temperature and the number of organs damaged within $72 \mathrm{~h}$ were the most correlated to the risk of in-hospital death. Although some patients were accurately diagnosed early and received cooling treatment, prolonged high body temperature could also increase the risk of death. This suggests that it is important to emphasize not only the timing of initiating early cooling but also the effect of cooling. According to the ROC analysis, both AUCs were higher, which suggested significant predictive significance for in-hospital death. The cutoff values of the duration of body temperature $>$ $38^{\circ} \mathrm{C}$ and the number of organs damaged within $72 \mathrm{~h}$ were $4.88 \mathrm{~h}$ and 6.5 , respectively. This suggests that if EHS patients did not achieve effective cooling within 4.88 $\mathrm{h}$ after onset, or if more than six organs were damaged within $72 \mathrm{~h}$ of onset, they had a higher risk of death in hospital.

\section{Conclusions}

Since the overall incidence of EHS is low and sporadic, few large-scale case studies have reported this population. The total number of recruited cases in this retrospective study was 214, which was relatively large compared to previous studies. Our results revealed that EHS continues to have high mortality. Among the factors involved in the early stage of the disease, gender, age, BMI, occupation, underlying diseases, ambient relative humidity, ambient temperature, time from onset to diagnosis, and initial body temperature were not significantly associated with the risk of in-hospital death, while the duration of body temperature $>38^{\circ} \mathrm{C}$ and number of organs damaged within $72 \mathrm{~h}$ of onset were the most significant risk factors and predictors of death. This suggests that EHS patients that do not achieve effective cooling within $4.88 \mathrm{~h}$ after onset or who have in excess of six damaged organs within $72 \mathrm{~h}$ of onset have a higher risk of death in hospital. These findings may provide some insights on the management of EHS to reduce the incidence of death at the early stage of onset.

\section{Abbreviations}

CHS, classic heat stroke; EHS, exertional heat stroke; CI, confidence interval; ROC, receiver operating characteristic curve; AUC, area under the curve; DIC, disseminated intravascular coagulation; ARDS, patients with acute respiratory distress syndrome; GCS, Glasgow Coma Scale; JAAM, Japanese Association for Acute Medicine.

\section{Data Sharing Statement}

The datasets used and/or analyzed during the current study are available from the corresponding author on reasonable request.

\section{Ethical Approval and Consent to Participate}

The researchers collected the data after the project was certified from the Research Ethics Committee, Sixth Medical Center, Chinese PLA General Hospital (permitted number: HZKY-PJ-2020-20). This study was conducted in accordance with the declaration of Helsinki. Written informed consent was obtained from all participants.

\section{Acknowledgments}

Many thanks to all the researchers of this study for their active contributions, they paid precious time and energy for the successful completion of this study. Many thanks to Expert Group of Heat Stroke Prevention and Treatment of Chinese PLA for their strong support to this study. These experts were distributed in various medical centers, which greatly facilitated the data collection.

Co first author: Shuyuan Liu and Ling Xing contributed equally to this paper. 


\section{Funding}

This study was supported by the military medical innovation project fund (18CXZ019, 18CXZ024), a Chinese military fund dedicated to prevention and control of heatrelated illness with no commercial interest.

\section{Disclosure}

The authors declare that they have no conflicts of interest for this work.

\section{References}

1. Liu SY, Song JC, Mao HD, et al. Expert consensus on the diagnosis and treatment of heat stroke in China. Mil Med Res. 2020;7(1):1.

2. Song Q, Mao HD, Liu SY. Definition and classification of heat illness. Med J Chin PLA. 2019;44(7):541-545.

3. Epstein Y, Yanovich R. Heatstroke. N Engl J Med. 2019;380 (25):2449-2459. doi:10.1056/NEJMra1810762

4. Al Mahri S, Bouchama A. Heatstroke. Handb Clin Neurol. 2018;157:531-545.

5. Armed Forces Health Surveillance Bureau. Update: heat illness, active component, U.S. Armed Forces, 2016. MSMR. 2017;24(3):9-13.

6. Carter R 3rd, Cheuvront SN, Williams JO, et al. Epidemiology of hospitalizations and deaths from heat illness in soldiers. Med Sci Sports Exerc. 2005;37(8):1338-1344. doi:10.1249/01.mss.00001748 95.19639.ed

7. Katch RK, Scarneo SE, Adams WM, et al. Top 10 research questions related to preventing sudden death in sport and physical activity. Res $Q \quad$ Exerc Sport. 2017;88(3):251-268. doi:10.1080/02701367.20 17.1342201

8. Yankelson L, Sadeh B, Gershovitz L, et al. Life-threatening events during endurance sports: is heat stroke more prevalent than arrhythmic death?. J Am Coll Cardiol. 2014;64(5):463-469. doi:10.1016/j. jacc.2014.05.025

9. Ni X, Liu Z, Xie Q, et al. Cerebral injury induced by heat stroke and the therapeutic effect of hyperbaric oxygen therapy. Zhonghua Wei Zhong Bing Ji Jiu Yi Xue. 2017;29(6):572-576.
10. Subspecialty Group of Acute and Intensive Cardiac Care of Chinese Society of Cardiology; Editorial Board of Chinese Journal of Cardiology. Chinese experts consensus on the diagnosis and treatment of cardiogenic shock (2018). Zhonghua Xin Xue Guan Bing Za Zhi. 2019;47(4):265-277.

11. Lou Y, Lin H, Wang $\mathrm{H}$, et al. Research progress in the heatstroke-induced myocardial injury. Zhonghua Wei Zhong Bing Ji Jiu Yi Xие. 2019;31(10):1304-1306.

12. Ranieri VM, Rubenfeld GD, Thompson BT, et al.; ARDS Definition Task Force. Acute respiratory distress syndrome: the Berlin definition. JAMA. 2012;307(23):2526-2533.

13. Thrombosis and Hemostasis Group, Hematology Society of Chinese Medical Association. Consensus of Chinese experts on diagnosis of disseminated intravascular coagulation (version 2017). Zhonghua Xиe Ye Xue Za Zhi. 2017;38(5):361-363.

14. Khwaja A. KDIGO clinical practice guidelines for acute kidney injury. Nephron Clin Pract. 2012;120(4):c179-184.

15. [No authors listed].Modified child-pugh classifications for liver function. Chin Arch Gen Surg. 2013;7(2):153. Chinese. doi:10.3760/cma.j.issn.1674-0793.2013.02.101

16. Blaser AR, Starkopf J, Fruhwald S, et al. Gastrointestinal function in intensive care patients: terminology, definitions and management. Recommendations of the ESICM working group on abdominal problems. Intensive Care Med. 2012;38(3):384-394. doi:10.1007/ s00134-011-2459-y

17. Zeller L, Novack V, Barski L, et al. Exertional heatstroke: clinical characteristics, diagnostic and therapeutic considerations. Eur J Intern Med. 2011;22(3):296-299. doi:10.1016/j.ejim.2010.12.013

18. Armed Forces Health Surveillance Center (AFHSC). Update: heat injuries, active component, U.S. Armed Forces, 2013. MSMR. 2014;21(3):10-13.

19. Laitano O, Leon LR, Roberts WO, et al. Controversies in exertional heat stroke diagnosis, prevention, and treatment. J Appl Physiol. 2019;127(5):1338-1348. doi:10.1152/japplphysiol.00452.2019

20. Bouchama A, Knochel JP. Heat stroke. $N$ Engl J Med. 2002;346 (25):1978-1988. doi:10.1056/NEJMra011089

21. Hifumi T, Kondo Y, Shimazaki J, et al. Prognostic significance of disseminated intravascular coagulation in patients with heat stroke in a nationwide registry. J Crit Care. 2018;44:306-311. doi:10.1016/j. jerc.2017.12.003
International Journal of General Medicine

\section{Publish your work in this journal}

The International Journal of General Medicine is an international, peer-reviewed open-access journal that focuses on general and internal medicine, pathogenesis, epidemiology, diagnosis, monitoring and treatment protocols. The journal is characterized by the rapid reporting of reviews, original research and clinical studies across all disease areas. The manuscript management system is completely online and includes a very quick and fair peer-review system, which is all easy to use. Visit http://www.dovepress.com/ testimonials.php to read real quotes from published authors. 